\title{
The Impact of Instant Messaging Tools on Knowledge Management and Team Performance
}

\author{
Carol X.J. Ou ${ }^{1}$, Darren W.L. Leung ${ }^{2}$, and Robert M. Davison ${ }^{3}$ \\ ${ }^{1}$ Department of Information Management, Tilburg University, The Netherlands \\ carol.ou@uvt.nl \\ ${ }^{2}$ Department of Computing, Hong Kong Polytechnic University, Hong Kong \\ 06245602D@polyu.edu.hk \\ ${ }^{3}$ Department of Information Systems, City University of Hong Kong, Hong Kong \\ isrobertacityu.edu.hk
}

\begin{abstract}
Instant messaging (IM) has become increasingly popular as a form of social communication. However, the adoption of IM in the workplace remains controversial due to the challenges associated with quantifying organizational benefits. In this study, we evaluate the effects of using IM tools on facilitating knowledge transfer and knowledge generation at work, and their subsequent influence on work performance. The proposed model is validated by a survey of work professionals at a small company with the support of a social networking diagram. Implications and conclusions are discussed.
\end{abstract}

Keywords: Instant messaging (IM), computer-mediated communication (CMC), knowledge transfer, knowledge generation, work performance.

\section{Introduction}

Advances in information technology have resulted in the development of various computer-mediated communication (CMC) tools of which the instant messenger (IM) is one of the most prevalent. An IM tool has the capability to overcome geographical distance and facilitate "instant" interaction among interlocutors. Researchers have demonstrated IM's potential in promoting multi-tasking, as well as improving working efficiency (Cho et al. 2005; Quan-Haase et al. 2005). For example, managers and employees often communicate with each other in multiple social networks: they are not embedded in a single workgroup (Teigland 2000). Given the flexibility provided by IM, organizations increasingly allow employees to use IM as a substitute for email as they engage on collaborative tasks.

On the other hand, many researchers and practitioners have pointed out that the interruptive nature of IM can negatively affect work efficiency and reduce productivity (Isaacs et al. 2002; Nardi et al. 2000). Consistent with academic research, Deloitte's (2010) recent survey revealed that only 41 percent of 750 participating companies allow using social networking tools such as IM in the workplace. The under-employment of IM at work may be largely due to IM's controversial impacts. 
Given the above dilemma, in this study we investigate the impact of IM on knowledge management (KM) in the workplace. $\mathrm{KM}$ is a key business process responsible for shaping organizational competitive advantage (Nonaka 1994). Prior research on KM has often focused on formal, enterprise-wide KM systems (KMS) (Bock et al. 2005). The impact of informal CMC tools, such as IM, on KM has been overlooked. We argue that by connecting working professionals in multiple social networks, IM has the potential to contribute to knowledge transfer and generation in the workplace, subsequently enhancing team performance.

In addition to investigating the contribution of CMC tools to $\mathrm{KM}$, we also use the social network analysis (SNA) technique to develop social network diagrams in order to visualize employees' or team members' email- and IM-based interactions. Furthermore, SNA results enable an examination of the correlation between the elements of social networks (including degree centrality, closeness centrality, betweenness centrality, density, and tie strength) and KM at work. These analyses and diagrams have the potential to render both theoretical and practical explanations with respect to $\mathrm{KM}$, where the network literature has previously provided few insights into the specific elements that facilitate knowledge transfer and generation.

In the following section, we propose a theoretical model, grounded on social network theories, to describe the impacts of IM and social networks on KM in the workplace. After describing how we conducted a survey in a small-sized company in Hong Kong, we then present a combined analysis of the research model and the social networks that we discovered. We conclude the paper with key findings, implications, contributions, and directions for future research.

\section{Theoretical Development}

We rely on social network theories (Granovetter 1973; Krackhardt 1992; Wellman et al. 1996) to develop the theoretical model about IM's impacts on KM and subsequent work performance. Specifically, Wellman et al. (1996) coined the term computer supported social networks because computer networks connect people. In networks such as those facilitated by the Internet, individuals can seek information and collaborate online when they leverage these new modes of synchronous and asynchronous communication. Granovetter's (1973) theory on the strength of weak

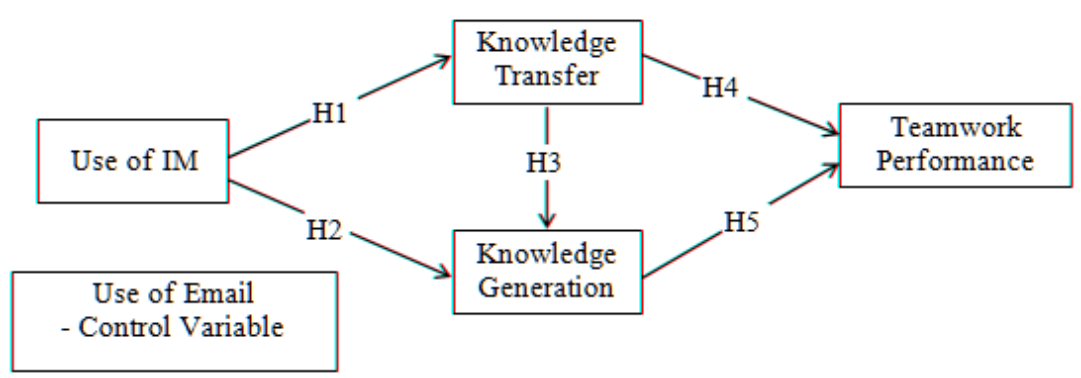

Fig. 1. The Proposed Research Model 
ties suggests that individual members of social networks obtain novel information from other members with whom they have weaker ties. However, while weak ties may be more useful for obtaining or soliciting new knowledge, strong ties play a role in facilitating the knowledge transfer process (Krackhardt 1992).

In this article, we draw on these social network theories to study the impacts of IM, as a social $\mathrm{CMC}$ tool, on facilitating $\mathrm{KM}$ and explore its downstream effects on work performance. Figure 1 outlines the research model. The definitions of constructs used are summarized in Table 1. We provide the detailed arguments on the proposed research model in the following sections.

Table 1. Definitions of Constructs and Source

\begin{tabular}{|l|l|l|}
\hline \multicolumn{1}{|c|}{$\begin{array}{c}\text { Principal } \\
\text { Constructs }\end{array}$} & \multicolumn{1}{|c|}{ Definitions } & \multicolumn{1}{c|}{ Source } \\
\hline Use of IM & $\begin{array}{l}\text { The use of IM tools as work-related contact and } \\
\text { communication tools to raise questions and perform } \\
\text { work-related socialization }\end{array}$ & $\begin{array}{l}\text { Cho et al. (2005); } \\
\text { Quan-Hasse et al. } \\
\text { (2005) }\end{array}$ \\
\hline $\begin{array}{l}\text { Knowledge } \\
\text { Transfer }\end{array}$ & $\begin{array}{l}\text { The extent to which the employee can explain their } \\
\text { key ideas, concepts and theories in their area of } \\
\text { expertise }\end{array}$ & $\begin{array}{l}\text { Reagans and } \\
\text { McEvily (2003) }\end{array}$ \\
\hline $\begin{array}{l}\text { Knowledge } \\
\text { Generation }\end{array}$ & $\begin{array}{l}\text { The extent to which the employee is able to generate } \\
\text { new solutions, ideas and ways of working as well as } \\
\text { facilitate organizational learning }\end{array}$ & Soo et al. (2002) \\
\hline $\begin{array}{l}\text { Teamwork } \\
\text { Performance }\end{array}$ & $\begin{array}{l}\text { The employees' perceptions of outcome satisfaction, } \\
\text { outcome quality and team satisfaction. }\end{array}$ & Fuller et al. (2006) \\
\hline
\end{tabular}

\subsection{The Impact of IM on Knowledge Transfer}

KM has been defined as the process of capturing, storing, sharing and using knowledge (Davenport et al. 1998). In these four processes, knowledge transfer occurs whenever knowledge is diffused from one individual to others (Roberts 2000). This diffusion can be effected through processes of socialization, education and learning (Roberts 2000). More specifically, both conceptual (e.g., Granvetter 1973; Krackhardt 1992) and empirical (e.g., Levin and Cross 2004) studies have suggested that weak ties within social networks foster information search activities, while strong ties facilitate knowledge transfer among individuals.

We argue that, IM, as a social CMC tool, connects work professionals in a network (see Wellman et al. 1996). IM can stimulate an instant interaction via the pop-up message dialogue feature. The bilateral, near-synchronous form of communication then enabled closely resembles the openness and transparency associated with faceto-face communication. Unlike traditional social networks, IM-enabled social networks are able to overcome the constraints imposed by temporal and spatial communication barriers which people often encounter in face-to-face social networks. With such rapid IM interaction, the development of strong ties between distributed team members no longer needs to rely on physical contacts.

By connecting people, IM tools provide work professionals with a valuable channel for sharing, transferring and documenting knowledge. During the interaction 
process, team members can clearly negotiate work expectations, explore social contexts and collaborate on team work (Cho et al. 2005). Indeed, the characteristics of tools used to transfer knowledge have been found to affect the success of knowledge transfer (Argote and Ingram 2000). IM's informal and casual characteristics make it easier for team members to transfer knowledge. IM, therefore, constitutes an effective CMC tool that can be used both for complex work collaboration and for simple task coordination. We thus propose that

Hypothesis 1: The use of IM enhances the ease of knowledge transfer in the workplace.

\subsection{The Impact of IM on Knowledge Generation}

Knowledge generation activities at work can occur in many different ways (Simon 1991). In addition to information processing, organizations often generate new knowledge through action and interaction (Levinthal and Myatt 1994). Scholars have suggested that knowledge generation requires intensive communication (Nonaka 1994). Indeed, smooth knowledge generation often requires a robust yet informal communication network (Soo et al. 2002), because interlocutors need tools such as images and other visual aids to help them to present their ideas to others.

We argue that IM is a very suitable tool to support the transmission of rich content. With such additional functions as file transfer and video conferencing, IM can serve as a functionally rich $\mathrm{CMC}$ tool that facilitates the knowledge generation process. Knowledge workers can leverage IM as a flexible and informal means to engage in intensive communication with their colleagues. Such information exchange allows new and innovative ideas to flow through and into the company.

As suggested by the theory of weak ties (Granovetter 1973), individuals often obtain more new information or ideas from weak ties than from strong ties within a social network. This is because weak ties play the role of an information "bridge" to connect different clusters of people who can then bring in new information. We argue that IM, in addition to facilitating intensive communication between strongly tied members of social networks, offers a valuable means to loosely connect people. The list of contacts maintained in an IM tool are not restricted only to close friends or colleagues, but also include less frequently contacted individuals. In this sense, the contact records in an IM tool can be leveraged for searching information and identifying new knowledge. IM provides a bridge for different clusters of people to get in touch when necessary and possibly to acquire new knowledge within a loosely connected social network. Putting the above arguments together, we therefore propose that

\section{Hypothesis 2: The use of IM facilities knowledge generation in the workplace.}

\subsection{Generating Knowledge via Knowledge Transfer}

Knowledge generation is often related closely to the expansion of the existing knowledge pool (Tracey et al. 2002). Knowledge itself is thus an important source for further knowledge creation. According to Nonaka (1994), the process of knowledge 
creation involves interactions between explicit and tacit knowledge. In the process of knowledge generation, individuals may find it relatively easier to access and integrate knowledge with colleagues located in other offices (Teigland and Wasko 2009), consistent with the theory of weak ties (Granovetter 1973).

We argue that facilitating knowledge generation by knowledge transfer can be enhanced by the IM-enabled work environment. The attributes of IM facilitate the conduct of searches for solutions or information across departments or even across national boundaries. By shaping the network structure, IM creates communication patterns that can affect knowledge structures, in terms of knowledge transfer and generation in organizations, and thus helps to spread knowledge widely within an organization. With the aid of IM tools in sharing visual, task-related information, mutual understanding and new knowledge is more likely to be generated. We therefore propose that

\section{Hypothesis 3: Knowledge transfer contributes positively to knowledge generation.}

\subsection{Enhancing Work Performance with Knowledge Transfer and Knowledge Generation}

In a highly competitive and turbulent environment, organizations need to modify their structures continually. Strategic knowledge generation is viewed as fundamental to an organization's development and to successfully building competitive advantage, especially in SMEs (Cantú et al. 2009). Increased frequency of interaction and knowledge sharing can enable more comprehensive consideration and comparison of alternative problem solutions. Such a knowledge sharing and transfer process can thus lead to improved decision making, which will ultimately improve work performance (Stasser and Titus 1985). Consistently, research (e.g., Srivastava et al. 2006) has provided empirical evidence for the positive relationship between knowledge sharing and teamwork performance.

The problems faced by companies have become more sophisticated in the current knowledge era. This situation often pushes companies to acquire or generate ever more innovative ideas in order to survive. This is especially true for SMEs, where there is little organizational slack. With new and innovative ideas flowing into work teams, SMEs may solve sophisticated problems more effectively, even with resource constraints. The greater the amount of knowledge that flows in to the organization, the greater the capability to solve problems in a more effective way (Soo et al. 2002). Meanwhile, the knowledge creation process will result in a stock of new knowledge and subsequently have a positive impact on the employees' performance in the workplace. As a result, team performance will be influenced by those individuals who are able and willing to apply new knowledge in making decisions. Taking the above arguments together, we hence propose that

Hypothesis 4: Knowledge transfer has a positive relationship with teamwork performance.

Hypothesis 5: Knowledge generation has a positive relationship with teamwork performance. 


\subsection{Analytical Elements of Social Networks, IM and KM}

From the SNA perspective, a social network refers to the social structure connecting individuals called nodes (Wasserman and Faust 1994). The structure itself is tied by one or more relationships which, in the workplace, may include friendship, common interest, knowledge exchange, collaboration, and collegiality (see Cho et al. 2005).

In this study, we focus on the interrelationships among IM, KM, and the analytical elements of a social network, including centrality, density, and tie strength. The literature on $\mathrm{KM}$ has provided rich insights into the contribution of interpersonal relationships on knowledge sharing (e.g., Bock et al. 2005; Chow and Chan 2008). However, the influence of the characteristics of interpersonal relationships and social networks (such as centrality, density, and tie strength) on effective KM is yet to be identified.

Wasserman and Faust (1994) provide clear definitions of the analytical elements (i.e., measures) of social networks for the purpose of SNA. Specifically, centrality refers to how well the nodes connect to the network, which can be measured by betweenness (the extent to which a node lies between other nodes in the network), closeness (the degree to which an individual is near other individuals in a network), and degree (the count of the number of ties to other actors in the network). Density represents the proportion of ties in a network relative to the total number possible. Tie strength refers to emotional closeness between individuals (Granovetter 1973), which can be quantitatively but vicariously measured by frequency of interaction, closeness and time known with other actors in a social network (Marsden 1990; Marsden and Campbell 1984).

We argue that the use of IM can strengthen these characteristics of social networks, given that it is widely used to connect people and maintain interpersonal relationships socially ( $\mathrm{Li}$ et al. 2005) as well as in the workplace (Cho et al. 2005). IM provides an effective communication channel to facilitate the collaboration among team mates or other organizational members at work, thus enhancing the connectivity of the interlocutors in social works in the workplace (i.e., centrality). It is easy to search for and add friends in the buddy list, facilitating the creation of "unforgettable" online contact lists and a well connected online network, and thus contributing to enhancing the density of social networks in the workplace. As explained in the previous sections, the instant interaction via IM can enable team members to clearly negotiate work expectations and explore social contexts (Cho et al. 2005), and thus help strengthen the strong work-related and interpersonal relationships among team members. We therefore hypothesize

Hypothesis 6: The use of IM is positively associated with centrality (H6a), density (H6b), and tie strength (H6c) of a social network.

The literature on KM has suggested that a strong interpersonal relationship encourages knowledge sharing and transfer (Bock et al. 2005; Szulanski 1996). From an SNA perspective, a dense and centralized network means individuals are well connected and individuals in the network know each other. We argue that density is positively associated with knowledge transfer. This is because a well connected 
network embeds some levels of cooperative relationship where everybody has the responsibility to cooperate and share knowledge. If the network members do not cooperate, non-cooperation behavior will spread quickly to other network members and restrict their future interaction (Reagans and McEvily 2003). However, we argue that a network characterized by an extremely high density and centrality (meaning nearly everybody connects with each other) may not be effective for generating new knowledge, since information is already available to everyone in the same social circle and little new knowledge may emerge. Such an argument is consistent with Granovetter's (1973) theory of the strength of weak ties. Specifically, Granovetter argues that weak ties facilitate the creation of new knowledge, while strong ties contribute to comprehensive knowledge transfer. This is because "weak ties provide people with access to information and resources beyond those available in their own social circle; but strong ties have greater motivation to be of assistance and are typically more easily available" (Granovetter 1983, p. 209). We therefore hypothesize

\section{Hypothesis 7: Knowledge transfer is positively associated with centrality $(\mathrm{H} 7 \mathrm{a})$, density $(\mathrm{H} 7 \mathrm{~b})$, and tie strength $(\mathrm{H} 7 \mathrm{c})$ of a social network.}

Hypothesis 8: Knowledge generation is negatively associated with centrality $(\mathrm{H} 8 \mathrm{a})$, density $(\mathrm{H} 8 \mathrm{~b})$, and tie strength $(\mathrm{H} 8 \mathrm{c})$ of a social network.

\subsection{Control Variables}

In addition to IM, email is commonly encountered in organizations as a means to facilitate social networking and knowledge management. We thus account for the effect of email in the research model by incorporating this construct in data analysis.

\section{Methodology}

We targeted a small-sized company in Hong Kong as our research focus. We used a survey to collect empirical data that was used to test the research model. We also undertook a social network analysis (SNA) of the survey data.

\subsection{The Research Context}

The company, which we refer to by the pseudonym of Version Limited, had 75 employees at the time of our study. The company is composed of six departments: sales, marketing, customer service, logistics, accounting, and IT. Version Limited conducts its business around the Asia Pacific area, including Hong Kong, Taiwan, China, and Singapore. Its main business is to develop and distribute communication systems, Internet software, security, network, and media products. The company is headquartered in Hong Kong, where there are two offices. It is a norm of Version Limited that every staff member, even the CEO, has an IM tool installed in their computer, enabling them to communicate with other colleagues as they wish. 


\subsection{The Measures}

We relied on existing measures to develop the survey questions. The independent variable, IM use at work, is measured by adapting scales from Kankanhalli et al. (2005) and Cho et al. (2005). Knowledge transfer is measured with the scale developed by Reagans and McEvily (2003). Knowledge generation is measured by adapting questions from Soo et al. (2002). Work performance is measured with scales developed and validated in Fuller et al. (2006). Teamwork performance is measured with three sub-constructs, viz., group satisfaction, outcome satisfaction, and outcome quality. Teamwork performance is operationalized in this study as a subjective measure at the individual level, rather than as an objective measure at the group level.

In addition to the above seven-point Likert-scale questions, the survey also includes the relational data collected for the SNA diagram for Version Limited. Specifically, the survey participants were asked to provide information on their interlocutors with respect to the frequency of contacting them using an IM tool and email, the length of time they had known each person, and perceived closeness. These data can be used to measure the "tie strength" of interlocutors in a social network (Granovetter 1973). A summary of all the measures used in the survey is available from the authors.

\subsection{Social Network Analysis (SNA) Technique}

Common SNA includes the calculation of several characteristics of a social network, viz., centrality, density, and tie strength where centrality is decomposed into degree centrality, closeness centrality, and betweenness centrality (Borgatti et al. 2002; Freeman 1978). The method used to calculate the relative degree centrality of an individual is to divide the number of direct connections (degree) by the network size:

$$
\text { Centrality (Degree) }=\frac{\text { Degree }}{\text { Network Size }}
$$

The typical way to measure the "closeness" of a point is that calculated from the sum distance, the sum of the geodesic distances to all other points in the graph (Sabidussi 1966). If the matrix of distances between points in an undirected graph is calculated, the sum distance of a point is its column or row sum in this matrix. In this research, we use the sum distance as the indicator of closeness that a point with a low sum distance is close to a large number of other points. We list the calculation of closeness centrality in formula (2).

$$
\text { Centrality }(\text { Closeness })=\sum_{i=1}^{n} \mathrm{~d}(\mathrm{Pi}-\mathrm{Pk})
$$

where $\mathrm{n}=$ number of vertices in the graph and $\mathrm{d}=$ geodesic distance from point $\mathrm{i}$ to point $\mathrm{k}$.

The calculation of betweenness centrality is based upon "the frequency with which a point falls between pairs of other points on the shortest or geodesic paths connecting 
them" (Freeman 1978, p. 221). In this sense, the betweenness of a point suggests "the extent to which an agent can play the pan of a 'broker' or 'gatekeeper' with a potential for control over others" (Scott 1988, p. 86). The centrality of Point $\mathrm{k}^{1}$ in terms of betweenness can be calculated with formula (3).

$$
\mathrm{CB}(\mathrm{Pk})=\sum_{\mathrm{i}}^{\mathrm{n}} \sum_{<j}^{\mathrm{n}} \mathrm{bij}(\mathrm{Pk})
$$

where $\mathrm{n}$ is the number of points in the graph.

Density is a measure of network cohesiveness and is the ratio of the existing number ties to the maximum ties possible. The number of lines in a graph is directly reflected in its inclusiveness and the degrees of its points (Scott 1988). We adopt the following (4) to calculate the density of the social network at Version Limited.

$$
D=\frac{t}{n(n-1) / 2}
$$

where $\mathrm{t}=$ number of direct connections with other actors. This measure can vary from 0 to 1 ; for an actor who has connections to all other individuals within the network, the result will be 1 .

In social network studies, emotional closeness is a commonly used indicator of tie strength resulting from extending Granovetter's (1973) theoretical notion on tie strength (e.g., Borgatti et al. 2002). Other indicators of tie strength include frequency of contact and time known (Marsden 1990; Marsden and Campbell 1984). The calculation of tie strength of an actor is measured as the average of all tie strengths in terms of frequency of interaction, closeness, and time known with all other actors within the network (as shown in Table 2).

Table 2. Item Use for Measuring Tie Strength

\begin{tabular}{|l|l|}
\hline \multicolumn{1}{|c|}{ Items } & \multicolumn{1}{c|}{ Scale used } \\
\hline Frequency of interaction & Five point likert scale (from daily to less often) \\
\hline Degree of closeness & Five point likert scale (from especially close to distant) \\
\hline Time known & Five point likert scale (from over 3 years to less than 6 months) \\
\hline
\end{tabular}

\subsection{Sample}

In this research, data were collected from employees of Version Limited on a voluntary basis. The employees were provided with both hard and soft copies of the survey questionnaire. Over a period of three weeks, we collected 43 responses, a

\footnotetext{
${ }^{1}$ According to such a measure, the larger the data related to centrality closeness between two individuals shown by the data actually suggests that they are more distant in reality. This means that a reverse scale has been used to measure the actual centrality closeness.
} 
response rate of 57 percent. Due to questions not answered, two responses were removed from the data analysis. Therefore, a total of 41 valid responses were available for analysis. Table 3 summarizes the demographic data of the respondents.

Table 3. Demographic Data of Respondents $(n=41)$

\begin{tabular}{|c|c|c|c|c|c|}
\hline Items & Indicators & Percent & Items & Indicators & Percent \\
\hline \multirow{2}{*}{ Gender } & \multirow[t]{2}{*}{$\begin{array}{l}\text { Male } \\
\text { Female }\end{array}$} & \multirow[t]{2}{*}{$\begin{array}{l}52.5 \% \\
47.5 \%\end{array}$} & \multirow{3}{*}{$\begin{array}{l}\text { Education } \\
\text { level }\end{array}$} & $\begin{array}{l}\text { Senior High School } \\
\text { or Technical School }\end{array}$ & $2.5 \%$ \\
\hline & & & & $\begin{array}{l}\text { Diploma/Associate } \\
\text { Degree }\end{array}$ & $32.5 \%$ \\
\hline \multirow[t]{4}{*}{ Age range } & $18-22$ & $40 \%$ & & Bachelor Degree & $65.0 \%$ \\
\hline & $23-25$ & $25 \%$ & \multirow{3}{*}{$\begin{array}{l}\text { Working } \\
\text { experience in } \\
\text { current } \\
\text { company }\end{array}$} & 6 Months - 2 Years & $50.0 \%$ \\
\hline & $26-30$ & $27.5 \%$ & & 2- 5 Years & $37.5 \%$ \\
\hline & $31-40$ & $7.5 \%$ & & More than 5 Years & $12.5 \%$ \\
\hline \multirow[t]{6}{*}{ Department } & Sales and Marketing & $37.5 \%$ & \multirow{6}{*}{$\begin{array}{l}\text { Number of } \\
\text { IMs used for } \\
\text { work }\end{array}$} & 1.00 & $72.5 \%$ \\
\hline & Customer Service & $32.5 \%$ & & 2.00 & $17.5 \%$ \\
\hline & Accounting & $10.0 \%$ & & 3.00 & $5.0 \%$ \\
\hline & Logistics & $10.0 \%$ & & 4.00 & $2.5 \%$ \\
\hline & IT & $7.5 \%$ & & 5.00 & $2.5 \%$ \\
\hline & Other & $2.5 \%$ & & & \\
\hline \multirow[t]{2}{*}{$\begin{array}{l}\text { Office } \\
\text { location }\end{array}$} & Mong Kok & $72.5 \%$ & \multirow{2}{*}{$\begin{array}{l}\text { Years of } \\
\text { using IM at } \\
\text { work }\end{array}$} & 1 - 5 Years & $22.5 \%$ \\
\hline & Science Park & $27.5 \%$ & & More than 5 Years & $77.5 \%$ \\
\hline
\end{tabular}

\section{Data Analysis}

We used the statistical package for the social sciences (SPSS) and partial least squares (PLS) to calculate the validity and reliability of the constructs and the robustness of the research model.

\subsection{Validating the Measurements}

First, the validity is confirmed by the factor analysis (omitted for brevity). All the eigenvalues of the constructs are larger than the suggested value of 1.0. The communality scores are higher than the suggested value (0.50). These results indicate adequate reliability of measures (Hair et al. 1995). Second, the reliability is validated by using Cronbach's alpha and composite reliability scores. Cronbach's alphas of all constructs range from 0.87 to 0.95 and all composite reliability are above 90 percent, which suggest acceptable internal consistency (Hair et al. 1995). The square roots of the average variance extracted (AVE) are greater than 0.8 (see Table 4), which are greater than all other cross correlations, implying that all of the constructs capture more construct-related variance than error variance (Pavlou and Gefen 2004). 
Table 4. Descriptive Statistics, Correlation Matrix, and AVE of Principal Constructs

\begin{tabular}{|l|l|l|l|l|l|l|}
\hline \multicolumn{1}{|c|}{ Principal Constructs } & $\begin{array}{c}\text { Composite } \\
\text { Reliability }\end{array}$ & \multicolumn{1}{|c|}{$\begin{array}{c}\text { Mean } \\
\text { (STD) }\end{array}$} & \multicolumn{1}{|c|}{ UIM } & \multicolumn{1}{|c|}{ KT } & KG & WP \\
\hline Usage of IM (UIM) & 0.91 & $5.58(1.06)$ & $\mathbf{0 . 8 5}$ & & & \\
\hline Knowledge Transfer (KT) & 0.92 & $4.91(1.01)$ & $0.55^{* *}$ & $\mathbf{0 . 8 9}$ & & \\
\hline Knowledge Generation (KG) & 0.96 & $4.6(1.26)$ & $0.37^{*}$ & $0.54 * *$ & $\mathbf{0 . 9 2}$ & \\
\hline Work Performance (WP) & 0.95 & $5.18(0.91)$ & $0.34^{*}$ & $0.62^{* *}$ & $0.39 *$ & $\mathbf{0 . 8 3}$ \\
\hline
\end{tabular}

*Significant at $\mathrm{p}<0.05 ; * *$ Significant at $\mathrm{p}<0.01$

\subsection{Testing the Research Model}

The structural model in this study was examined with PLS. As shown in Figure 2, the results indicate that all hypotheses, except $\mathrm{H} 2$ and $\mathrm{H} 5$, are supported by the data. IM use at work has a significant positive effect $(b=0.48, p<0.01)$ on knowledge transfer, supporting H1. Together with the usage of email at the workplace, the usage of IM at work explains 41 percent of the variance of knowledge transfer. The direct influence of the usage of IM on facilitating knowledge generation is moderate $(\mathrm{b}=$ -0.02 , p > 0.01), rejecting H2. Regarding the impact of knowledge transfer on knowledge generation, the results provide support for $\mathrm{H} 3(\mathrm{~b}=0.31, \mathrm{p}<0.01)$. Knowledge transfer also has a significant effect on performance at the workplace $(\mathrm{b}=$ $0.66, \mathrm{p}<0.01$ ), validating H4. However, the path from knowledge generation to work performance is not significant $(b=0.12, p>0.01)$, rejecting H5. Knowledge transfer and generation explain 54 percent of the variance of work performance. In sum, the $\mathrm{R}^{2}$ scores for all dependent variables and the high factor loadings yield an adequate goodness-of-fit for the overall research model (Chin 1998).

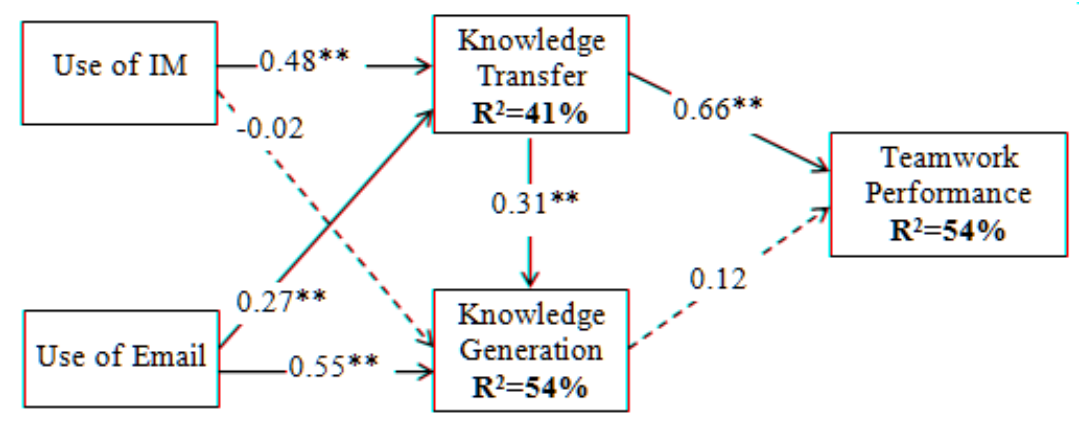

$*$ Significant at $\mathrm{p}<0.05, * *$ Significant at $\mathrm{p}<0.01)$

Fig. 2. PLS Results of Structural Model

\subsection{Social Network Analysis (SNA)}

With the collected data from the name generation process, a social network diagram for Version Limited is drawn using UCINET 7, relying on the calculations explained 
in the methodology (Figure 3). A total of 41 respondents participated in the name generation process with a total of 69 unique names produced as a result. To protect the participants' privacy, we use a symbol, instead of the participant's real name, in the diagram to present an individual employee at Version Limited. We discuss the corresponding insights drawn from the SNA diagram in the next section.

In addition to the SNA, we also use SPSS to perform a correlation analysis among IM usage and the attributes of the social network at Version Limited. The results of the correlation analysis indicate that the use of IM has a significant effect on some of the components of SNA (see Table 5).

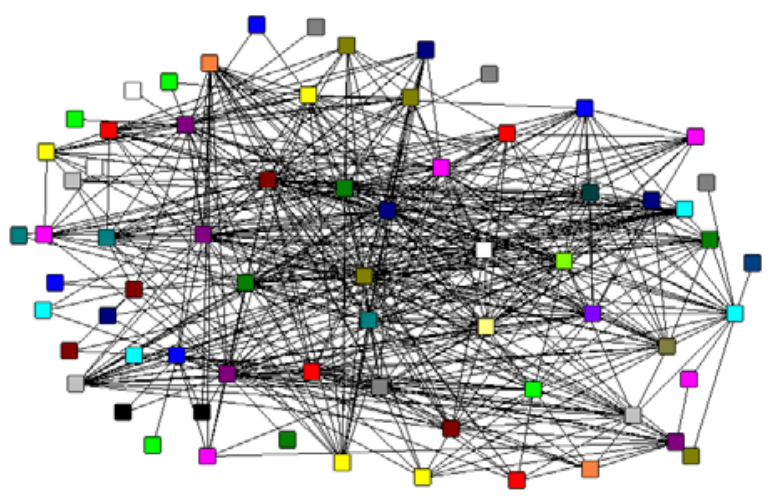

Fig. 3. Social Network Diagram

Table 5. Correlation Table of Usage of IM and Social Network Components

\begin{tabular}{|c|c|c|c|c|c|c|}
\hline & Use of IM & DC & $\mathrm{CC}$ & BC & Density & TS \\
\hline Degree Centrality (DC) & $0.37 * *$ & & & & & \\
\hline Closeness Centrality $(\mathrm{CC})^{2}$ & $-0.37 * *$ & 0.13 & & & & \\
\hline Betweenness Centrality (BC) & 0.21 & $0.61 * * *$ & $0.41^{* * *}$ & & & \\
\hline Density & $-0.42^{* * *}$ & $-0.56^{* * *}$ & -0.19 & $-0.72^{* * *}$ & & \\
\hline Tie Strength ${ }^{3}$ & $0.29 *$ & $0.71^{* * *}$ & 0.08 & 0.23 & $-0.36^{* *}$ & \\
\hline Knowledge Generation (KG) & $0.37^{* *}$ & $0.32 * *$ & $-0.35 * *$ & 0.09 & -0.19 & $0.29^{*}$ \\
\hline Knowledge Transfer (KT) & $0.56 * 4 *$ & 0.17 & -0.18 & -0.05 & -0.21 & $0.33^{* *}$ \\
\hline Work Performance (WP) & $0.34 * *$ & -0.04 & -0.08 & -0.05 & -0.10 & 0.23 \\
\hline
\end{tabular}

*Significant at $0.05<\mathrm{p}<0.10 ; * *$ Significant at $0.01<\mathrm{p}<0.05 ; * * *$ Significant at $\mathrm{p}<0.01$

The correlation analysis results shown in Table 5 indicate that the data supports H6a $(b=0.37, p<0.01$ for IM with degree centrality and close centrality) and H6c ( $b$ $=.029,0.05<\mathrm{p}<0.10)$, but rejects H6b $(\mathrm{b}=-0.42, \mathrm{p}<0.01)$. Knowledge transfer is found to be positively associated with tie strength $(b=0.33, p<0.01)$, thus validating $\mathrm{H} 7 \mathrm{c}$. We found significance neither in the correlation between knowledge transfer and centrality, nor in the correlation between knowledge transfer and density, thus 
rejecting $\mathrm{H} 7 \mathrm{a}$ and $\mathrm{H} 7 \mathrm{~b}$. Opposite to the hypotheses of $\mathrm{H} 8 \mathrm{a}, \mathrm{H} 8 \mathrm{~b}$, and $\mathrm{H} 8 \mathrm{c}$, data suggest knowledge generation is more effective in a social network characterized by high centrality, density, and tie strength. We discuss these key findings and corresponding implications in the next section.

\section{Key Findings, Implications and Future Research}

\subsection{Findings Related to the Research Model}

This research has a number of key findings. IM tools are well accepted as a social networking technology. This study provides empirical evidence that using IM tools at work can exert a positive effect on work performance via effective technology transfer. Although IM's direct effect on knowledge generation is not significant, the analytical result indicates that IM use is highly correlated with knowledge generation $(\mathrm{b}=0.37, \mathrm{p}<0.05)$. Our post hoc analysis indicates that knowledge transfer fully mediates the direct relationship between use of IM and knowledge generation. This full mediation effect suggests knowledge transfer is the building block of knowledge generation in the workplace. In other words, the easier it is for individuals to share knowledge with other colleagues, the more likely it is that new knowledge will be generated; however, the mere existence of IM is not sufficient for knowledge generation.

Surprisingly, our data did not support the hypothesis that knowledge generation at work will improve teamwork performance. This unexpected outcome can be explained as follows. In KM, one of the factors affecting knowledge sharing activities within an organization is the willingness of individuals to share the knowledge acquired or created by them (Bock et al. 2005). If the individual obtains new knowledge to solve a problem but decides not to share it, the overall performance of the team or the firm may not be enhanced (Gibbert and Krause 2002). Version Limited does not reward individuals who contribute new knowledge to the company. Thus, even if the employees have new knowledge or new ways of solving problems, the new knowledge may not necessarily be brought to the team or organization level. Therefore, knowledge generation at the individual level has much less influence on the overall improvement of the team or organization work performance.

\subsection{Findings Related to the Social Network Analysis (SNA)}

Figure 3 visualizes the major social network at Version Limited. According to this SNA, we include the means and standard deviations (STD) of the five critical characteristics of the social network, viz., tie strength, degree centrality, betweenness centrality, closeness, and density. Our post hoc analysis of the social network at Version Limited suggests the social network enabled by IM is averagely dense (with a mean density of 0.48 out of 1 ). The average network size is 20 . The betweenness of the social relationships varies considerably (with a mean of 61 and STD of 85). Five survey participants serve as "gate keepers" of the social network, with a betweenness value higher than 200. The average centrality degree is low at 0.30 (maximum of 1 ). This data suggests that there is still room for developing an efficient and well connected social network at Version Limited. 
Table 5 suggests the significance of IM in building the social network at Version Limited. The use of IM is significantly correlated with all characteristics of the social network including degree centrality, closeness centrality, betweenness centrality, density, and tie strength. Specifically, the correlation between IM use and degree centrality $(b=0.37, p<0.05)$ implies that IM has enabled a quick and simple communication channel for users that will probably increase the ease of communicating and encourage people to have more interactions with their colleagues even if they are located in different offices. Closeness centrality is measured by the distance among individual network members. The significantly negative correlation between IM and closeness centrality $(b=0.27, p<0.05)$ implies that the distance of an individual from other people should be reduced when they use IM tools more frequently. Notably, the use of IM is negatively related to density of the network. Such a finding suggests the use of IM can create a sparse network. This is indeed consistent with the above social network diagram, which suggests that Version Limited only has a moderately dense network. IM tools can be used as a valuable means to maintain occasional contacts (i.e., people with weak ties) that are accessed only when necessary. IM tools thus help to spread the social network around. The data also implies the use of IM helps strengthen the ties between social actors $(b=0.29,0.05<p<0.10)$. Taking all of these results together, the use of IM appears to strengthen the whole social network at Version Limited.

Tie strength, as proposed by Granovetter (1973), is expected to be positively correlated with knowledge transfer, but negatively correlated with knowledge generation activities. Our data provided strong support for the correlation between tie strength and knowledge transfer $(b=0.33, \mathrm{p}<0.05)$. However, our analysis also indicated that tie strength contributes to knowledge generation $(b=0.29,0.05<p<$ 0.10). We suspect that in this IT-focused, knowledge-intensive company, employees are linked to different knowledge pools through different network links. When knowledge-intensive work is involved, strong ties foster complex knowledge transfer where complexity of knowledge is directly associated with the tacitness of knowledge (Hansen 1999). Meanwhile, the generation of new knowledge relies on the interaction of tacit and explicit knowledge (Nonaka 1994). Accordingly, strong ties facilitate faster and more complex knowledge transfer including highly tacit knowledge which is required for new knowledge generation during the process of tacit and explicit knowledge interaction. Therefore, the importance of strong ties for work professionals in a company's social network cannot be discounted for the individuals in knowledgeintensive work to perform.

\subsection{Theoretical and Practical Implications}

Prior research (e.g., Cho et al. 2005; Quan-Haase et al. 2005) has provided a foundation to investigate the significance of IM in enhancing social networks and work performance. The current study conceptualizes IM's contribution to knowledge management, considering its valuable capability in enabling work professionals to instantly share and transfer specific knowledge to each other in real time. The utilization of the constructs of knowledge transfer and knowledge generation in IMenabled communication provides social network studies a theoretical angle to investigate the effects of social networking tools in knowledge management as well as the subsequent impacts on teamwork or the organization as a whole. 
At the same time, IS-related social networking has received increased attention from both academics and practitioners. Most research has examined the social network as a whole and investigated its characteristics. Relying on the SNA technique, in this study we explored more specific components of a social network (including centrality, density, and tie strength) and the relationship between the social networking tool (i.e., IM) with those components. This research provides a springboard for further research on the effectiveness of other social network tools in shaping the social network.

Practically speaking, with the advancement of information and communication technologies, applications of information technologies have been found both useful and effective for individuals, groups, organizations, and society at large. This research provides compelling reasons for organizations to utilize effective communication technologies such as IM at work to improve performance. The flexibility and informality of IM allow employees to retain control of communication in the workplace, task activities, and team work. IM tools can be used to record and codify knowledge in the online interaction process. The online conversation transcripts can be easily made available for other work professionals looking for similar ideas or knowledge. In this sense, IM can effectively function as a productivity tool that facilitates real-time exchange of knowledge.

\subsection{Future Research}

The current study provided empirical evidence on the positive contribution for the adoption of IM tools in the workplace by facilitating the process of knowledge management. Future research can usefully evaluate the negative values that are associated with the use of IM tools (e.g., interruption to operations, security issues, etc.). By including the negative impacts of IM used at work, we can achieve a more complete overview for the adoption of IM tools in the workplace.

In terms of analysis, this study measured perceived teamwork performance at the individual level. Future research can aggregate teamwork performance at the individual level to a group level for a more comprehensive analysis. Analytical rigor can be further enhanced by collecting both subjective and objective measures for all constructs used in the research.

Due to the constraints associated with the company studied, we only investigated one social networking tool (i.e., IM) in this research. However, IM is not the only social networking tool that can be used in organizations. Other Web 2.0 tools, such as Facebook and Twitter, can also be applied to knowledge management activities, as well as marketing and product design (Deloitte 2010). Research into both theoretical and empirical aspects of the utilization of social networking tools in the organizational context will enrich our understanding of the relationships among social networks, IT, and the SNA technique, as well as how social networking tools can render a competitive advantage for organizations.

\section{Conclusion}

A well-connected social network in the workplace can augment the organization's collective knowledge and sharpen its capability to act on what people know in time. 
By connecting people with various social networking tools, such as IM, blogs, Facebook, and Twitter, the organization can become an effective web of interaction. This study provides a compelling rationale to embed social network tools into the organizational context. The technology related to social networking tools is evolving. We believe more theoretical and practical research will emerge in this field.

\section{References}

Argote, L., Ingram, P.: Knowledge Transfer: A Basis for Competitive Advantage in Firms. Organizational Behavior and Human Decision Processes 82(1), 150-169 (2000)

Bock, G.W., Zmud, R.W., Kim, Y.-G., Lee, J.N.: Behavioral Intention Formation in Knowledge Sharing: Examining the Roles of Extrinsic Motivators, Social-Psychological Forces, and Organizational Climate. MIS Quarterly 29(1), 87-111 (2005)

Borgatti, S.P., Everett, M.G., Freeman, L.C.: UCINet for Windows: Software for Social Network Analysis. Analytic Technologies, Harvard (2002)

Cantú, L.Z., Criado, J.R., Criado, A.R.: Generation and Transfer of Knowledge in IT-Related SMEs. Journal of Knowledge 13(5), 243-256 (2009)

Chin, W.W.: Issues and Opinion on Structural Equation Modeling. MIS Quarterly 22(1), vii-xvi (1998)

Cho, H.-K., Trier, M., Kim, E.: The Use of Instant Messaging in Working Relationship Development: A Case Study. Journal of Computer-Mediated Communication 10(4) (2005)

Chow, W.S., Chan, L.S.: Social Network, Social Trust and Shared Goals in Organizational Knowledge Sharing. Information and Management 45, 458-465 (2008)

Davenport, T.H., Prusak, L.: Working Knowledge. Harvard Business School Press, Boston (1998)

Deloitte: Resistance to Change, Budget Constraints and Cost-Cutting Delay New Technologies into the Workplace. Deloitte Poll (2010)

Freeman, L.C.: Centrality in Social Networks: Conceptual Clarification. Social Networks 1(3), 215-239 (1978)

Fuller, M.A., Hardin, A.M., Davidson, R.M.: Efficacy in Technology-Mediated Teams. J. of Management Information Systems 23(3), 209-235 (2006)

Gibbert, M., Krause, H.: Practice Exchange in a Best Practice Marketplace. In: Davenport, T.H., Probst, G.J.B. (eds.) Knowledge Management Case Book: Siemens Best Practices. Publicis Corporate Publishing, Erlangen (2002)

Granovetter, M.S.: The Strength of Weak Ties. The American Journal of Sociology 78(6), 1360-1380 (1973)

Granovetter, M.S.: The Strength of Weak Ties: A Network Theory Revisited. Sociological Theory 1, 201-233 (1983)

Hair, J.F., Anderson, R.E., Tatham, R.L., Black, W.C.: Multivariate Data Analysis with Readings, 4th edn. Prentice Hall, Englewood Cliffs (1995)

Hammer, M.: Explorations into the Meaning of Social Network Interview Data. Social Networks 6, 341-371 (1984)

Hansen, M.T.: The Search-Transfer Problem: The Role of Weak Ties in Sharing Knowledge Across Organization Subunits. Administrative Science Quarterly 44(1), 82-111 (1999)

Isaacs, E., Walendowski, A., Whittaker, S., Schiano, D., Kamm, C.: The Character, Functions, and Styles of Instant Messaging in the Workplace. In: Proceedings of the 2002 ACM Conference on Computer Supported Cooperative Work, New Orleans, LA, pp. 11-20 (2002) 
Kankanhalli, A., Tan, B.C.Y., Wei, K.K.: Contributing Knowledge to Electronic Knowledge Repositories: An Empirical Investigation. MIS Quarterly 29(1), 113-143 (2005)

Krackhardt, D.: The Strength of Strong Ties: The Importance of Philos In Organizations. In: Nohria, N., Eccles, R. (eds.) Networks and Organizations: Structures, Form and Action, pp. 216-239. Harvard Business School Press, Boston (1992)

Levin, D.Z., Cross, R.: The Strength of Weak Ties You Can Trust: The Mediating Role of Trust in Effective Knowledge Transfer. Management Science 50(11), 1477-1494 (2004)

Levinthal, D., Myatt, J.: Co-Evolution of Capabilities and Industry: A Study of Mutual Fund Processing. Strategic Management Journal 15, 45-62 (1994)

Li, D., Chau, P.Y.K., Lou, H.: Understanding Individual Adoption of Instant Messaging: An Empirical Investigation. The Journal of the Association for Information Systems 6(4), 102-129 (2005)

Marsden, P.: Network Data Measurement. Annual Review of Sociology 16, 435-463 (1990)

Marsden, P., Campbell, K.E.: Measuring Tie Strength. Social Forces 63, 482-501 (1984)

Nardi, B., Whittaker, S., Bradner, E.: Interaction and Outeraction: Instant Messaging in Action. In: Proceedings of the 2000 ACM Conference on Computer Supported Cooperative Work, Philadelphia, PA, pp. 79-88 (2000)

Nonaka, I.: A Dynamic Theory of Organizational Knowledge Creation. Organization Science 5(1), 14-37 (1994)

Pavlou, P.A., Gefen, D.: Building Effective Online Marketplaces with Institution-Based Trust. Information Systems Research 15(1), 37-60 (2004)

Quan-Haase, A., Cothrel, J., Wellman, B.: Instant Messaging for Collaboration: A Case Study of a High-Tech Firm. Journal of Computer-Mediated Communication 10(4) (2005)

Reagans, R., McEvily, B.: Network Structure and Knowledge Transfer: The Effects of Cohesion and Range. Administrative Science Quarterly 48, 240-267 (2003)

Roberts, J.: From Know-How to Show-How: Questioning the Role of Information and Communication Technologies in Knowledge Transfer. Technology Analysis \& Strategic Management 12(4), 429-443 (2000)

Sabidussi, G.: The Centrality Index of a Graph. Psychometrika 31, 581-603 (1966)

Scott, J.: Social Network Analysis: A Handbook. SAGE Publications, London (1988)

Simon, H.A.: Bounded Rationality and Organizational Learning. Organization Science 2(1), 125-134 (1991)

Soo, C., Devinney, T., Midgley, D., Deering, A.: Knowledge Management: Philosophy, Processes, and Pitfalls. California Management Review 44, 129-150 (2002)

Srivastava, A., Bartol, K.M., Locke, E.A.: Empowering Leadership in Management Teams: Effects on Knowledge Sharing, Efficacy, and Performance. Academy of Management Journal 49(6), 1239-1251 (2006)

Stasser, G., Titus, W.: Pooling of Unshared Information in Group Decision Making: Biased Information Sampling during Discussion. Journal of Personality and Social Psychology 48, 1467-1478 (1985)

Szulanski, G.: Exploring Internal Stickiness: Impediments to the Transfer of Best Practices Within the Firm. Strategic Management Journal 17, 27-43 (1996)

Teigland, R.: Communities of Practice at an Internet Firm: Netovation vs. On-Time Performance. In: Lesser, E.L., Fontaine, M.A., Slusher, J.A. (eds.) Knowledge and Communities: Resources for the Knowledge-Based Economy, pp. 151-178. ButterworthHeinemann, Woburn (2000)

Teigland, R., Wasko, M.: Knowledge Transfer in MNCs: Examining How Intrinsic Motivations and Knowledge Sourcing Impact Individual Centrality and Performance. Journal of International Management 15(1), 15-31 (2009) 
Tracey, P., Clark, G.L., Lawton Smith, H.: Cognition, Learning and European Regional Growth: An Agent-Centred Perspective on the "New" Economy. Economics of Innovation and New Technology 13(1), 1-18 (2004)

Wasserman, S., Faust, K.: Social Network Analysis: Methods and Applications. Cambridge University Press, Cambridge (1994)

Wellman, B., Salaff, J., Dimitrova, D., Garton, L., Gulia, M., Haythornthwaite, C.: Computer Networks as Social Networks: Collaborative Work, Telework, and Virtual Community. Annual Review of Sociology 22, 213-238 (1996)

\section{About the Authors}

Carol X. J. Ou is an assistant professor of Information Management at Tilburg University. Her research interests include social networks, computer-mediated communication, electronic commerce, website design, and knowledge management in organizations. Her publications have appeared in in such journals as Communications of the ACM, Journal of AIS, International Journal of Human-Computer Studies, Information Technology \& People, Journal of IT Management, and Chinese Management Studies. Carol is also serving as a senior editor for Information Technology \& People, Electronic Journal of Information Systems in Developing Countries, and International Journal of E-Adoption. She is a Certified IS Auditor, an Academic Advocate of IS Audit and Control Association, as well as a committee member of various conferences on information systems and technologies.

Darren W. L. Leung is a Bachelor of Computing student at the Hong Kong Polytechnic University. His research focuses on social networks and knowledge management in organizations.

Robert M. Davison is an associate professor of Information Systems at the City University of Hong Kong. His current research focuses on virtual knowledge management and collaboration in Chinese SMEs. He has published over 50 articles in a variety of journals such as Information Systems Journal, Information Technology \& People, IEEE Transactions on Engineering Management, Decision Support Systems, Journal of the AIS, Communications of the AIS, Communications of the ACM, and MIS Quarterly. Robert is the editor-in-chief of Electronic Journal of Information Systems in Developing Countries, a senior editor for Information Systems Journal, coeditor of Information Technology \& People, and an associate editor for MIS Quarterly. 